\title{
societies
}

ISSN 2075-4698

www.mdpi.com/journal/societies

Article

\section{Against the Use of Knowledge Gained from Animal Experimentation}

\section{Rebecca Tuvel}

Department of Philosophy, Rhodes College, 2000 N. Parkway, Memphis, TN 38112, USA;

E-Mail: tuvelr@rhodes.edu; Tel.: +1-901-843-3586

Academic Editor: Chloe Taylor

Received: 7 November 2014 / Accepted: 11 March 2015 / Published: 23 March 2015

\begin{abstract}
While there exists considerable protest against the use of animals in experimentation, less protest is voiced against the use of knowledge gained from animal experimentation. Pulling from arguments against the use of Nazi data, I suggest that using knowledge gained from animal experimentation both disrespects animal victims and sustains the practice. It is thus pro tanto morally wrong.
\end{abstract}

Keywords: animal experimentation; knowledge gained from evil; Nazi data

\section{Introduction}

While there exists considerable protest against the use of animals in experimentation, less protest is voiced over the use of knowledge gained from animal experimentation. ${ }^{1}$ Instead, there is a widespread consequentialist belief that if experimentation has already taken place, use of its epistemic benefits is morally permissible. ${ }^{2}$ After all, would it not be a further insult to the dead animal to refuse the

1. The infliction of pain to and the death of animals in experimentation receives attempted justification on several grounds, including to "advance knowledge, test and devise medical and non-medical products...[and] determine...toxicity levels” [1] (p. 17). Since all of these purposes serve to enhance knowledge in one way or another (e.g., how toxic is this product?), I speak broadly about animal experimentation's results as epistemic. When I refer to animal experimentation, I intend the "use of live animals in research in the biological, psychological and medical technological sciences” [2] (p. 6).

2 According to Hugh LaFollette, most people embrace a "common view”, which holds that "although (a) there are moral limits on what we can do to (some) nonhuman animals; (b) humans can use them when doing so advances significant human interest” [3] (p. 796). This broadly consequentialist thought employs a cost-benefit type of reasoning, such that even those who are against animal experimentation itself may still justify use of the practice's results (since the 
knowledge for which the animal was killed, not to mention harmful to the humans whose lives may be helped or even saved by the experiment's results? On this view, morality not only permits, but demands the use of knowledge gained from an admittedly immoral practice.

In this paper, I argue against the idea that the use of knowledge gained from animal experimentation is permissible. Rather, I suggest that sanctioning the epistemic benefits of animal experimentation both disrespects animal victims and sustains the practice. It is thus pro tanto morally wrong. ${ }^{3}$ This argument has implications not only for use of the experiments' results, but for the experiments themselves. Indeed, to the degree that animal experimentation's continued existence is predicated on the usability of its results, then an inability to justify the use of these results effectively blocks the main justification for the experiments themselves. Without this justification in place, animal experimentation as an ongoing practice cannot be defended. In addition to challenging the epistemic benefits of animal experimentation, this argument thus provides an alternative route to challenging the practice itself.

First, I describe why animal experimentation is morally wrong. Next, I canvass some arguments against the use of Nazi data. I then consider the relevance of these arguments for the case at hand. I conclude that two of these arguments (the victim disrespect and practice encouragement concerns) are sufficiently compelling to generate a pro tanto reason against the use of knowledge gained from animal experimentation.

\section{The Case against Experimentation}

In order to make the pro tanto case against the use of knowledge gained from animal experimentation, I first need to show that animal experimentation is morally wrong. To do so, I will show that it qualifies as wrong on both deontological and consequentialist grounds. First, since deontological animal rights theory holds that sentient animals deserve rights that protect them from being used as a means to an end, animal experimentation is wrong on this view. Second, I show that the amount of animal interests frustrated in experimentation, coupled with the fact that the results of animal experimentation do not translate well to humans, renders the practice morally wrong on consequentialist grounds.

\subsection{Animal Rights Theory: The Case against Experimentation}

Human rights theory holds that human beings possess basic interests that ought never to be violated. These interests are so strong that they merit rights, a kind of protective shield that safeguards them from violation. No matter how great a benefit is at stake, then, your right to life trumps any reason I may have to violate it (save for cases in which my basic rights are also at stake, e.g., self-defense). Accordingly, the inviolable rights view holds that "a person cannot be killed in order to harvest her body parts, even if dozens of other humans might benefit from her organs, bone marrow, or stem cells. Nor can she be made a subject of non-consensual medical experimentation, no matter how much the

deed is already done). Moe and Martin hold this type of position in relation to the use of data gained from Nazi experimentation [4,5].

3 As Shelly Kagan describes it, "a pro tanto reason has genuine weight, but nonetheless may be outweighed by other considerations...a prima facie reason appears to be a reason, but may actually not be a reason at all” [6] (p. 17). 
knowledge gained from experimenting on her would help others” [7] (p. 19). In short, her basic interest in living, and the right to life afforded by this, trumps any justification that would violate that right.

Most people think that humans alone deserve inviolable rights, because they uniquely possess certain capacities (e.g., the ability to reason, to use language, to plan or to be moral, to name a few popular contenders). Yet the problem with this argument is that not all humans thought to deserve rights share whatever capacity is deemed necessary for rights. For instance, people with severe cognitive disabilities deserve inviolable rights, yet may not share the capacity to be rational or use language. The same goes for infants and some persons with mental illness. This argument (famously known as the argument from marginal cases) poses one of the strongest challenges to efforts to accord rights uniquely on the basis of species.

What, then, does ground a claim to inviolable rights? According to some animal rights theorists, it is the capacity for sentience, the ability to be aware of one's surroundings and to experience pain, that grounds this claim. "Conscious/sentient beings are selves - that is, they have a distinctive subjective experience of their own lives and of the world" [7] (p. 25). They are vulnerable "to pleasure and pain, to frustration and satisfaction, to joy and suffering, or to fear and death" [7] (p. 25). On this view, if a being is sentient, then that being has certain basic interests in need of protection. Sentient beings thus deserve inviolable rights, including the right not to be experimented on against their will.

Several have objected to the argument that animal sentience supports a claim to inviolable animal rights. According to Carl Cohen, even if animal sentience may generate certain obligations on the part of humans to animals, it cannot generate anything close to animal rights. The reason is that animals are of a fundamentally different kind from humans, such that "rights pertain to [humans] as humans", and never to animals [8] (p. 37, my emphasis). However, given that he recognizes the strength of the argument from marginal cases (which, to repeat, establishes that not all humans share any one capacity that uniquely grants them rights), Cohen is at pains to explain why humans and animals are of a morally different kind. If they do not all share one capacity that grants them moral status, then why is being a member of the kind "biologically human" morally relevant [9] (p. 52)? As Nathan Nobis explains, "we share, little, morally, with human cells in flasks or organs in an icepack; bare biology doesn't count for much" [9] (p. 57). Absent the ability to rely on some supposedly shared human capacity, Cohen's kind principle amounts to pure speciesism, or the arbitrary privileging of one's species over another. ${ }^{4}$

Perhaps one might try to draw the line elsewhere, though. One could simply argue that it is not humans per se who deserve rights, but those capable of higher cognition. This principle is not

4 Moreover, it is irrelevant that some or most humans possess the requisite property for moral inclusion (e.g., rationality or language), for other humans cannot gain the property "being a member of the moral community" by mere association [9] (p. 53). Nathan Nobis explains: “Consider a case where you'd wish this principle were true: you are a student (A) in a class who has failed the exams and done none of the homework, so on your own merits, you are failing. However, fortunately for you, the rest of the students have the properties of 'passing the exams and done well on the homework' (C) and, on that basis, have the property (R), passing the course.' If Cohen's principle were true, you too would have the property of passing the class, as well, because you are a member of the kind (K) 'students taking this class', and the properties from the majority transfer to you. Unfortunately for you, this property you would possess only on your own merits (which you lack, since you have failed the exams and have done none of the work), so Cohen's principle is false” [9] (p. 53). 
speciesist, the objector maintains, because it excludes not only animals incapable of higher cognition, but humans incapable of higher cognition, too. On this view, it turns out that most humans, the great apes and dolphins, for instance, deserve rights, but many animals, infants and cognitively disabled people do not. The problem with this view is that it leaves the latter category of beings completely vulnerable to violation. And since we should be "horrified at the suggestion that it is acceptable to use such people as forced organ donors or as non-consenting subjects in biomedical experiments, even if we did so 'humanely,'” this position is unacceptable [10] (p. 17).

To consider one final reason why rights ought not to hinge on higher cognition, animal rights theorists Sue Donaldson and Will Kymlicka enjoin us to imagine Telepaths. Telepaths are an alien species with cognitive capacities far beyond our own, including their impressive capacity to communicate telepathically [7] (p. 27). Imagine that Telepaths come to Earth, enslave the human race and defend their actions on the grounds that humans have inferior mental capacities [7] (p. 27). Naturally, we, the enslaved, would think the Telepaths morally abhorrent [7] (p. 28). Regardless of our relatively feeble capacities, humans would protest, "we have our own lives to lead, our own experience of the world, our own sense of how our lives go better or worse" [7] (p. 28). Insofar as the same is true for animals, we cannot condemn the Telepaths' violation of human rights without also condemning humans' violation of animal rights [7] (p. 28).

In sum, animal rights theory shows why animal experimentation is morally wrong. As a matter of consistency, if we think that all sentient humans deserve the right not to be subject to experimentation against their will, we must likewise hold that all sentient animals deserve this right.

\subsection{Consequentialism: The Case against Experimentation}

According to consequentialism, one ought to perform whatever act will produce the most good. As a species of consequentialism, utilitarianism defines good consequences as those that increase the welfare of all affected beings. Although what constitutes welfare (or well-being) differs depending on the account, for our purposes, welfare can be understood in terms of the satisfaction of interests. In making moral decisions, then, the utilitarian will try to weigh the interests of all affected beings and choose the act that produces the highest level of interest-satisfaction. On this view, if killing me can save five others, all else being equal, it would be right to frustrate my interest in life to satisfy the interests of the five.

Like several animal rights theorists (see $[7,10]$ ), utilitarian animal ethicists agree that sentience-the capacity for "suffering and/or enjoyment or happiness" — grants a being equal moral consideration [11] (p. 7). As early utilitarian Jeremy Bentham famously put it, the question is not "Can they reason, nor can they talk, but, can they suffer?” [11] (p. 7). The capacity for suffering is important, as Peter Singer explains, because it is "a prerequisite for having interests at all” [11] (p. 7). We do not speak of a table's interests, because, as a non-sentient object, it has none. However, "a mouse [...] does have an interest in not being kicked along the road, because it will suffer if it is” [11] (p. 8). Finally, equal moral consideration means that if a being has an interest in not suffering, that interest gets to be “counted equally” with the similar interests of any other being [11] (p. 8). In sum, since most animals have an interest in not suffering, this interest ought to be included and counted equally in the utilitarian calculation of interests. 
Once animals' interests are included in the utilitarian calculation, many human practices involving animals are no longer justified. For instance, the immense amount of animal pain and suffering that over eight billion animals endure in U.S. factory farms alone each year has been well documented [12] (p. 756). For a utilitarian, this amount of suffering is so extreme that the human interests satisfied by consuming meat cannot possibly outweigh it. As Singer puts it, since "none of these practices cater for anything more than our pleasures of taste, our practice of rearing and killing other animals in order to eat them is a clear instance of the sacrifice of the most important interests of other beings in order to satisfy trivial interests of our own” [13] (p. 223).

However, unlike factory farming, much animal experimentation appears to serve non-trivial human interests, so could it be justified on utilitarian grounds? It is true that animal experimentation could in theory be justified on utilitarian grounds. This is especially true for Singer, who maintains that "it is not arbitrary to hold that the life of a self-aware being, capable of abstract thought, of planning for their future, of complex acts of communication, and so on, is more valuable than the life of a being without these capacities” [11] (p. 20). According to this view, since a being with self-awareness who is capable of abstract thought is likely to have greater interests than a being without these capacities, it could be permissible to sacrifice a being with lesser interests for the sake of the being with greater interests. And although not all humans are capable of these so-called higher capacities (e.g., infants and the severely cognitively disabled) and neither are all animals incapable of them (e.g., chimpanzees, dogs, pigs), since most humans are capable and most animals incapable of these capacities, human interests will on average outweigh animal interests. Leaving aside the many concerns that have been voiced over this position (see Francione [10], Kittay [14] et al.), since the interests of beings with "higher" capacities can be sacrificed for the interests of beings with "lower" capacities on this view, utilitarianism entails that animal experimentation could theoretically be justified. ${ }^{5}$

However, justification in theory is different from justification in practice. And in practice, animal experimentation cannot be justified on utilitarian grounds. The reason is two-fold. First, animal experimentation causes immense animal pain and distress for often frivolous human purposes. Second, of the experiments that do serve important human interests (e.g., medical experiments), the results are often of dubious relevance to humans. For these reasons, the utilitarian calculation of interests will not favor animal experimentation.

\subsection{Animal Pain and Distress in Experimentation}

Since governments do not require researchers to keep track of how many rats, mice, fish, birds, frogs or invertebrates they use in experimentation, it is impossible to know precisely how many animals are used in experimentation [15] (p. 25). However, according to estimates by Taylor and

5 Although Singer has been accused otherwise, he maintains that his account is not speciesist. This is because, controversially, not only do non-self-aware animals have fewer interests than self-aware humans on his view, but non-self-aware humans have fewer interests as well. As Singer writes, "whenever experimenters claim that their experiments are important enough to justify the use of animals, we should ask them whether they would be prepared to use a brain-damaged human being at a similar mental level to the animal they are planning to use. [...] What difference is there between the two? Only that one is a member of our species and the other is not? But to appeal to that difference is to reveal a bias no more defensible than racism or any other form of arbitrary discrimination” [11] (p. 82-83). 
colleagues, in 2005, 37 countries used a total of 50.4 million animals for experimentation ([16], quoted in [17]). In the U.S. context, the United States Department of Agriculture (USDA) reports that 1,134,693 animals were used in American laboratories in 2010 and 953,077 animals in 2012 [18]. These numbers include cats, dogs, guinea pigs, hamsters, marine mammals, primates, pigs, rabbits, sheep and other unnamed animals, but exclude mice, rats and fish. Although we cannot be certain of the numbers, it is estimated that approximately 80,000,000 mice and rats are used annually in the U.S. [15] (p. 26).

Nearly all animals used in experimentation are capable of experiencing pain and distress. Indeed, this is often what makes them useful models. As Andrew Knight explains, "almost all animals used in laboratories are higher vertebrates, such as mammals, birds, reptiles, and amphibians, which possess the neuroanatomical and psychological capacities necessary to experience significant pain, fear, and psychological distress" [17] (p. 35). Yet similar to the difficulty involved in estimating the exact numbers, it is difficult to estimate how much pain and distress animals undergo in experimentation [15] (p. 27). ${ }^{6}$ Not only is it a challenge to quantify animal pain and distress [15] (p. 27), but the classification of "minor" to "moderate" to "severe" pain or distress necessarily involves subjective interpretation. ${ }^{7}$ However, some criteria are in place to help judge levels of pain and distress in animals. These include watching for "altered heart rate, abnormal breathing or muscle twitching", "impaired activity”, "personality changes such as increased aggression”, "restlessness”, “changes in dietary intake and behavior”, "abnormal vocalization”, “abnormal posture” or "self-mutilation” [2] (p. 95).

Of the three main purposes for which experimental animals are used-to develop pharmaceutical/ medical products, to advance scientific research and to test toxicity levels [19] (p. 21) — the vast majority involves some level of animal pain and/or distress. Indeed, insofar as the goal of much animal experimentation is to "model severe human injuries and illnesses", it is difficult to deny that many animals experience pain and distress in experimentation [20] (p. 1). Moreover, although experimenters are expected to use anesthetics to alleviate animal pain, they are not required to if doing so would interfere with the experiment's results [20] (p. 1). ${ }^{8}$ For instance, in recent studies to test new drugs for arthritis pain, no painkillers were given to a control group of animals (while the other group received relief only if the drugs work) [20] (p. 1). This is characteristic of pain therapy studies generally [21] (p. 222).

It is safe to say that when animals are used as models for human disease, they experience pain and distress. Animals have been used as models for nearly all human diseases, including cancer, AIDS, diabetes, Lou Gehrig’s disease and Alzheimer’s [22] (p. 32). Consider cancer. As Carbone notes, "virtually every human cancer is modeled in animals, and as in people, some cancers (such as oral and bone cancers) appear to be quite painful, even in their early stages” [20] (p. 2). It has been estimated that one carcinogenetic study alone used over 1200 animals [17]. In such studies, animals are made to

6 Pain can be defined as "the detection and signaling of a noxious stimulus", while suffering can be defined as "the affective, behavioral or emotional response to the pain” [2] (p. 93).

7 As Vaughan Monamy notes, "it may be argued that it is not possible to describe to another the pain one is feeling, or to comprehend another person's misery” [2] (p. 93).

8 Carbone notes that "The AWA (Animal Welfare Act), the Guide for the Care and Use of Laboratory Animals, and current Public Health Service policy all allow for the conduct of what are often called " Category E”' studies-experiments in which animals are expected to undergo significant pain or distress that will be left untreated because treatments for pain would be expected to interfere with the experiment” [20] (p. 1). 
absorb or, in the case of tobacco, inhale carcinogenic substances. These procedures are said to account for some of the highest levels of pain and distress animals experience in experimentation [17] (p. 63). One paper describes the process as follows: “...in order to simulate human smoking patterns, a 2-s puff from a burning cigarette is diluted with air and forced into a chamber for a short period, followed by an air purge. However, animals that are being forced involuntarily to inhale the smoke suffer avoidance reactions and change their breathing patterns to shallow, hesitant inspirations...” [23] (p. 973). ${ }^{9}$ The pain animals undergo in carcinogenicity studies is also long term; rodents are initially dosed when they are 6-8 weeks old and continue to be dosed for 90-110 weeks, at the end of which (if they survive), they are killed [17] (p. 63). Moreover, since it is notoriously difficult to control for pain in cancer patients, most animal pain is not alleviated in these cases [20] (p. 2). ${ }^{10}$ Furthermore, even if it could provide some relief, since pain medication can delay the progression of cancer, it may complicate the research and thus not be used [20] (p. 2).

There are many other areas of experimentation in which animals experience pain and distress. Animals are used in toxicology studies that test household cleaners, pesticides, cosmetics and chemicals for toxic effects on animals [24] (p. 46). In acute oral versions of these tests, animals are force-fed substances by mouth or by way of a tube inserted down their throats, after which they "often display classic symptoms of poisoning, including vomiting, diarrhea, paralysis, convulsions, and internal bleeding” [11] (p. 53). In one such test, the lethal dose 50 (LD50), it is expected that half (or 50 percent) of subjects will die [2] (p. 63). Before they die, the animals are very sick and in clear pain and distress [11] (p. 54). Animals are also used in skin irritation tests, like the well-known Draize eye irritancy test. In these tests, animals (often rabbits) are restrained and a potentially toxic substance, such as a household cleaner, is dropped into the animal's eye [25] (p. 70). One researcher describes a rabbit's reaction thus: "Total loss of vision due to serious internal injury to cornea or internal structure. Animal holds eye shut urgently. May squeal, claw at eye, jump and try to escape” [11] (p. 54).

Animals are also used in mutagenicity studies that test products to see if they will produce genetic mutations, as well as in reproductive toxicity studies that test chemicals to see whether they will cause miscarriages, infertility or birth defects [2] (p. 63). Animals are used in neurological research that may involve the infliction of brain damage on animals and in bone and joint research in which animals' bones are fractured or injured [24] (p. 46). They may also be used for research on "depression, drug addiction, aggressive behavior, communication, learning and problem solving, normal and abnormal social behavior, reproduction and parental care” [2] (p. 61). Some of this research may involve no pain or suffering, such as when monkeys' responses to the playback of alarm calls is observed, while others involve clear pain and suffering, such as in electric shock or maternal deprivation experiments respectively [2] (p. 61).

9 The study itself admits that comparisons between humans and animals are dubious: “Cigarette smoke has been tested for carcinogenicity by inhalation studies in rodents, rabbits and dogs. The model systems for animal exposure to tobacco smoke do not fully simulate human exposure to tobacco smoke, and the tumours that develop in animals are not completely representative of human cancer. Nevertheless, the animal data provide valuable insights regarding the carcinogenic potential of tobacco smoke” [23] (p. 1185).

10 As Carbone writes, "successful pain treatment [in humans] can require an intravenous catheter for round-the-clock medication. This would be an extremely unlikely and challenging management strategy for rodents on cancer studies” [20] (p. 2). 
Animals not only experience pain and distress directly in experimentation, but also in relation to laboratory confinement. In their assessments of the ethics of animal research, institutional animal care and use committees (IACUCs) do not factor in animals' experiences in laboratories when they are not undergoing research [26] (p. 175). Yet, as Robert Streiffer argues, since animals are confined for the purpose of later research and since confinement is a "ubiquitous aspect of the lives of almost all research animals”, it is relevant to an ethical assessment of the research itself [26] (p. 175).

Streiffer argues that although confinement properly understood is not ipso facto harmful to animals (or humans), it is clear that many laboratory confinement conditions are harmful to animals. So, although laboratories may provide some benefits to animals in the form of veterinary care, a regular diet and protection from external threats, like predators and bad weather, laboratory confinement is also associated with boredom, frustration, lack of access to conspecifics and species-typical behaviors [26] (pp. 183-184). Fear and chronic stress are also common in animals who live in less-than-ideal laboratory environments, particularly for those who have been captured from the wild [17] (p. 36). In general, the confinement conditions in laboratories lead to notably distressed behavior in animals. Consider the case of rabbits:

Because most are not surgically sterilized, [rabbits] are kept alone in small, steel cages to prevent fighting and unwanted reproduction, and typically have nothing to play with and nothing to do. Rabbits, like other laboratory animals, are often observed engaging in stereotypic behaviors associated with emotional and psychological deprivation, such as bar licking, excessive grooming, or paw chewing, and sitting in a hunched position for hours at a time. The cages are too small to permit normal behaviors such as sitting up on hind legs, hopping, digging, and hiding. In addition, they often either undereat or overeat to counter their boredom; and many develop deformities in the spine and legs because they can't move freely in the tiny spaces [27] (p. 79).

In addition to these straightforward physical and psychological harms, some have argued that laboratory confinement frustrates animals' interests in other ways. As Michael Allen Fox notes, "when we inflict pain or suffering on animals, we harm them. However, harm may also result when we confine or socially isolate them, deprive them of the ability to behave in ways natural to their species, or kill them” [28] (p. 58). For instance, according to natural function theorists, an animal's ability to engage in species-typical behavior or to exercise natural capacities contributes to that animal's well-being [26] (p. 183). On this view, "a mouse who can burrow into a substrate or a monkey mother who can nurse her baby has a life that goes better in a way" [26] (p. 183). Among other things, natural function theorists sometimes argue that conditions of confinement prevent animals from exercising the species-typical behavior of autonomy [26] (p. 187). Lori Gruen defines autonomy as involving the ability to "make choices about what to do, when to do it, and who to do it with" and that many animals exhibit such abilities when they plan, save tools, hide food for later use or engage in manipulation or deception [29] (p. 148). Insofar as many laboratories not only confine animals, but also control nearly every aspect of animals' lives and choices, including whether they can reproduce, when and what they can eat and who to live and interact with [30] (p. 163), laboratories also frustrate animals' interests in autonomy. 
Whether due to pain, distress or a lack of autonomy, animals' most basic interests are frustrated in experimentation. In light of this, we should not be surprised to learn that animals have often tried to escape laboratory environments. In 2009, for instance, nine snow monkeys managed to escape from an Oregon animal testing lab after a cleaner forgot to lock a cage door (all were found and returned to the lab three days later) [31]. Mice are also "known escape artists”, and will readily flee if a cage door is left unfastened [32]. For anyone who doubts that animals are harmed by experimentation in the above ways, minimally their efforts to resist and flee whenever possible suggests they are harmed by it in some way.

\subsection{Benefits to Humans}

As mentioned earlier, if sufficiently important human interests are at stake, animal experimentation could be justified on utilitarian grounds. However, important human interests are often not at stake in animal experimentation, leading Singer to argue that "among the tens of millions of experiments performed, only a few can possibly be regarded as contributing to important medical research" [11] (p. 40). Indeed, as discussed above, animals are used for all sorts of purposes aside from medical ones, including for commercial products, like makeup and cleaning items, and for non-medical research and basic pedagogy in many university departments [11] (p. 40). Perhaps it will be conceded that, if they involve animal suffering, these experiments do not serve human interests sufficiently important to outweigh this suffering and, so, are wrong on utilitarian grounds. But what about important biomedical experiments? Are the benefits to humans sufficiently great to outweigh the frustration of animals' interests in these cases?

Perhaps most damaging to the case for animal experimentation is the fact that medical experiments often do not yield usable results for humans. According to one estimate, "95\% of drugs found safe and effective on nonhuman animal tests are rejected as harmful or useless during human clinical trials” [33] (p. 90; quoted in [34]). For instance, although it revealed no negative effect on pregnant "dogs, cats, rats, monkeys, hamsters and chickens”, the drug thalidomide caused severe defects in over 10,000 human babies [11] (p. 57). ${ }^{11}$ There are countless examples of drug trials like this. David Sztybel elaborates:

Tuberkulin cures tuberculosis in guinea pigs but causes it in humans. The arthritis medicine, oraflex, was safe and effective on animals but kills humans, and indeed guinea pigs can safely eat strychnine, while sheep can consume large quantities of arsenic. Digitalis, a cardiac drug that has saved millions of human lives, was delayed in its release because it dangerously elevates blood pressure in dogs. The discoverers of penicillin are grateful that no guinea pigs were available for testing, for it kills these small animals. Morphine causes mania in cats and mice, and dogs have twenty times the tolerance for it that humans do. Cases such as these abound. Nonhuman animals make very poor models for predicting results for human beings, and it is doubtful whether they help us to predict at all even when the humans and nonhumans are similarly affected by treatments: we just do not know in advance, in any given case. And allowing us to know in advance is supposed to be the whole point of animal experimentation [34] (p. 178).

11 Deformities were produced only in a specific strain of rabbit [11] (p. 57). 
Such troubling cases have led several physicians and scientists to question the usefulness of animal experimentation [11] (p. 56). As an American Medical Association (AMA) representative once put it, "frequently animal studies prove little or nothing and are very difficult to correlate to humans" [11] (p. 58). Similarly, as scientist and executive director of the American Council on Science and Health, Elizabeth Whelan, notes, “it doesn't take a Ph.D. in the sciences to grasp the fact that rodent exposure to the saccharin equivalent of 1800 bottles of soda pop a day doesn't relate well to our daily ingestion of a few glasses of the stuff” [11] (p. 57).

Of course, this is not to suggest that animal experimentation never yields useful knowledge for humans. Animal experimentation has certainly played a role in the creation of many vaccines, drugs and other products that have greatly benefited humans [29] (p. 118). As the American Medical Association writes, "virtually every advance in medical science in the 20th century, from antibiotics to vaccines to antidepressant drugs and organ transplants, has been achieved either directly or indirectly through the use of animals in laboratory experiments” [3] (p. 800). Moreover, it has been argued that alternatives to animal experimentation, like human cells and tissue cultures, cannot yield knowledge anywhere as useful as studies on living organisms [3] (p. 801). On this view, complex human behavior can only be modeled on similarly complex beings, not on computers [3] (p. 801).

However, several responses are due. To the first point, since medical researchers are often legally required to experiment on animals, it is true that animal experimentation has played a role in nearly every medical advance [3] (p. 802). Yet, as Hugh LaFolette argues, that animal experimentation played a role in every medical advance does not mean it played an important or causally relevant role [3] (p. 802). As LaFolette points out, "Virtually all biomedical scientists drank milk as infants. However, that does not establish that milk drinking leads to biomedical knowledge” [3] (p. 802). Moreover, since they may not be useful or relevant, failed experiments on animals that played a less causally relevant role are likely to be under-reported in medicine [3] (p. 803). Indeed, surveys have revealed chronic problems with reporting in scientific research on animals generally, giving added cause for concern [35].

Second, the reason that there is often discontinuity between a product's effects on animals versus its effects on humans is that although they are similar, animals and humans are also importantly different. So although both humans and animals are "highly organized, intact systems", it is important not to overstate the similarities between them [3] (p. 807). LaFolette elaborates:

Species differences are evident even in closely related species: humans and New World monkeys use different metabolic pathways. Why do these differences matter? Because researchers often speak as if the condition or disease being studied in laboratory animals strongly resembles the condition in humans. Evolutionary theory suggests that is not a plausible expectation. We thus have reason to think that nonhuman animals are not, in general, strong models of human biomedical phenomena [3] (pp. 809-810).

In presuming that animals make good models for humans, we not only run into the danger of falsely assuming that certain drugs or products are safe for humans, but we may also lose out on drugs or products that are dangerous to animals yet safe for humans [11] (p. 57). For instance, insulin, morphine and penicillin all produced negative effects in infant rabbits and mice, mice and guinea pigs, respectively [11] (p. 57). Had we taken experiments of these drugs on animals seriously, humans may 
have never benefited from them. In short, as far as benefits to humans are concerned, animal experimentation may preclude us from important discoveries more often than it contributes to them.

Moreover, it is important that any assessment of the benefits of animal experimentation consider the practice as a practice. LaFolette aptly notes that the moral issue is never about one single experiment and its potential benefits to humans, for a single experiment never leads to a discovery [3] (p. 814). Rather, "all scientific experiments are part of a pattern of activity—an institutional practice-and discoveries are made through an organized pattern of experimentation" [3] (p. 814). The question is therefore whether the practice of animal experimentation as a whole can be justified, not simply this or that experiment. Framed in this way, it becomes clear that, as a practice, animal experimentation always produces a concrete harm to animals for a merely possible benefit to humans [3] (p. 817). This is because scientists can never know for sure whether an experiment will prove beneficial (and, as we have seen, many experiments produce no benefit at all) [3] (p. 817). As a practice, then, we can never say that animal experimentation will benefit humans [3] (p. 817).

Finally, LaFollette also argues that we should not speak of the benefits animal experimentation could produce, but the benefits that "only it could produce" [3] (p. 818, my emphasis). If animal experimentation's benefits could be attained through alternatives, then we must not weigh the "purported benefits of experimentation, but only the increase in benefits relative to alternatives” [3] (p. 818). Indeed, if the practice of animal experimentation were abolished, then presumably we could spend more energy on developing alternatives to it. ${ }^{12}$ This would increase the likelihood that alternatives could produce benefits just as good as, if not better than animal experimentation, thus closing the gap between the benefits due to animal experimentation and those due to alternatives.

This section was intended to show that animal experimentation is morally wrong on both deontological and consequentialist grounds. Whether it is because sentient animals deserve inviolable rights, protection from pain, distress and harmful laboratory confinement or because animal experimentation's purported benefits to humans do not outweigh animals' interests in not suffering, there are plenty of reasons why animal experimentation is morally wrong.

I will now turn to consider arguments against the use of knowledge gained from evil, specifically the use of Nazi data. ${ }^{13}$ However, before doing so, it will be important to say something about the term

12 Indeed, many viable alternatives to animal experimentation exist, including, but not limited to, human-tissue in vitro testing, human stem-cell research, and micro-dosing technology. Since they do not require animal suffering, the existence and promise of such alternatives (several of which are cheaper and more reliable than the use of animal models) renders the utilitarian case for animal experimentation especially precarious. Thanks to Mylan Engel Jr. for this point.

13 Many would object to the effort to analogize the case of animal experimentation to that of Nazi experimentation on the grounds that it is offensive to the memory of Holocaust victims. Consider, for instance, the uproar that ensued following PETA's 2003 campaign entitled "Holocaust on your plate", which placed images of concentration camp inmates alongside images of caged animals. One PETA tagline read: “To animals, all humans are Nazis” (invoking a similar line by Jewish writer Isaac Bashevis Singer) [36] (p. 98). In response, several Jewish groups and individuals called the exhibit “outrageous, offensive... abhorrent” and a "reprehensible misuse of Holocaust materials” [37]. Of course, such comparisons must always be made with the utmost care (for instance, they should not be made as claims to identical oppressions (see Sztybel [36], Painter [38])). However, we should also remain critical of objections to such comparisons on speciesist grounds. That is, one should object to claims that the comparison is offensive, because Holocaust victims mattered morally, whereas animals qua animals matter less or not at all. Once speciesist objections are pushed aside and the analogy is understood not as a claim to identical oppressions, I think the comparison becomes instructive, not only 
"evil”. Since the literature on Nazi data describes such cases in terms of products of evil, I retain the use of this term. However, the precise meaning of "evil” is vague. I follow Claudia Card's definition of evil as a "harm that is (1) reasonably foreseeable (or appreciable); and (2) culpably inflicted (or tolerated, aggravated, or maintained); and that (3) deprives, or seriously risks depriving, others of the basics that are necessary to make a life possible and tolerable or decent (or to make a death decent)" [40] (p. 16). Card further defines a tolerable life as a life "at least minimally worth living for its own sake and from the standpoint of the being whose life it is, not just as a means to the ends of others" [40] (p.16). On this definition, to commit evil, one need not have evil motives, but simply be culpable, i.e., be doing something wrong [41] (p. 163). Note further that on Card's view, "wrongdoing is necessary but not sufficient to make something evil. A wrongdoing is evil when it causes intolerable harm to others” [41] (p. 163).

As the preceding section served to show that intolerable harm, culpable wrongdoing and the lack of a decent life for animals are all characteristic of animal experimentation, then animal experimentation can properly be deemed evil on Card's definition. In fact, Card herself denies that only humans can be victims of evil and that her own view "includes evils done to animals" [40] (p. 9).

\section{Knowledge Gained from Evil}

Much ink has been spilled over whether it is permissible to use knowledge gained from evil. As a foremost example, consider the debates in bioethics over the use of Nazi data. ${ }^{14}$ As the Nuremberg trials revealed, the Nazis performed and documented horrific human experiments at several concentration camps [42] (p. 103). As in animal experimentation, victims were subject to pain and suffering for tests that were in most cases expressly intended to end in death. These include hypothermia experiments that submerged victims into ice water until they froze to death, high altitude experiments that dissected victims' brains while they were still alive, experiments to test intravenous poison injections and forced artificial insemination and sterilization. Hitler's biographer, Allan Bullock, describes the experiments as follows:

Among the other uses to which concentration-camp prisoners were put was to serve as the raw material for medical experiments by S.S. doctors. None of the post-war trials produced more macabre evidence than at the so-called "Doctors" Trial. All the experiments were conducted without anaesthetics or the slightest attention to the victims' sufferings. Amongst the ordeals to which they were subjected were intense air pressure and intense cold until the "patient's" lungs burst or he froze to death; the infliction of gas gangrene wounds; injection with typhus and jaundice; experiments with bone grafting; and a large number of investigations of sterilization (for "racial hygiene”), including castration and abortion. According to a Czech doctor who was a prisoner at Dachau and who personally

for its ability to shed light on the gravity of the human use of animals, but since "the commodification and exploitation of women, racialized peoples, and animals are indelibly linked and mutually sustaining”, also to understand better human oppression [39] (pp. 38-39).

14 In relation to the debate over morally-tainted Nazi data discussed below, see Moe [4], Martin [5], Schafer [43], Post [44]. Ridley [45], Godlovitch [46], Zion [47], Cohen [42] and Plaisted [48] et al. 
performed some seven thousand autopsies, the usual results of such experiments were death, permanent crippling, and mental derangement (quoted in [36] (p. 108)).

It goes without saying that Nazi experimentation constitutes an instance of evil. Yet, given that these experiments also gave rise to data ${ }^{15}$ that could be useful today, a moral dilemma arises. On the one hand, some think it would be immoral to refrain from using Nazi data. Consider Kristen Moe's point that even though Nazi experimentation was egregiously unethical, we should not "let the inhumanity of such experiments blind us to the possibility that some 'good' may be salvaged from the ashes" ([4] (p. 41) quoted in [42]). ${ }^{16}$

On the other hand, given the severity of the evil involved, many have objected to the use of these data. The Environmental Protection Agency (EPA), for one, considered using Nazi data in the development of air pollution regulations on phosgene, an industrial chemical used in pesticides and plastics in the U.S. [42] (p. 109). Whereas the EPA had no viable means of testing the effects of phosgene on human populations, the Nazis ran such experiments on over fifty prisoners in preparation for a possible phosgene attack on Germany by the Allies [42] (p. 110). These experiments resulted in relevant data on the effects of phosgene, data that could be instrumental in saving lives today. Despite the potential utility of these data, however, the EPA decided against using them. Similarly, the New England Journal of Medicine declined to publish Nazi data that could have been useful for hypothermia research [42] (p. 108).

What best accounts for the decision to forgo the use of Nazi data? There are three main categories of argument typically invoked to justify the idea that the use of Nazi research is immoral: (1) the character pollution concern; (2) the victim disrespect concern; and (3) the practice encouragement concern. I will canvass these concerns, arguing that the second and third provide the most convincing arguments in favor of the idea that the use of knowledge gained from evil is at least pro tanto morally wrong. I will echo Dennis Plaisted's summary and assessment of the character pollution concern and agree with him that this concern both appears to "condemn too many things" and to misplace the moral

15 As Stan Godlovitch notes, this data includes, for example, information derived from hypothermia experiments regarding tolerance to cold and ways to revive people gone unconscious from hypothermia [46] (p. 2). Interestingly, himself a major animal activist, Godlovitch also invokes, but does not develop, a comparison to animal experimentation: "I must add - though this will play no role in the discussion - that I can find no interesting moral difference between these research cases, so graphic to us now, and the current daily routine use of other animals by researchers worldwide" [46] (p. 2).

16 This parallels thoughts that a refusal to use knowledge from animal experimentation means the animal died in vain and resonates with the popular idea that it is more respectful to an animal that we use all its parts than to "waste” it. On this view, morality is commensurate with use. As an example of this view, Chloë Taylor describes a hunter colleague of hers who claimed he was a fellow animal activist, because he makes sure to use every part of the animal he kills, making "household items of their fat, fur, skin and bones” [49] (p. 88). However, Taylor notes that using "parts” and eating meat are never considered moral in relation to humans [49] (p. 86). Rather, they are considered signs of utmost depravity. If we learned, for instance, that human bodies were being dug up for a newfound energy resource, moral outrage (rather than moral approbation) would ensue. Indeed, far from profiting without consent from human death or suffering, respectful attitudes toward dead humans typically involve mourning rituals and efforts to grant humans dignity by fulfilling their wishes [49] (p. 97). Taylor concludes that the speciesist Western worldview "is deontological with respect to dead humans and utilitarian with respect to dead animals of other species” [49] (p. 97). 
focus on users rather than victims. However, I depart somewhat from Plaisted and others in my assessment of the latter two categories.

The first category is the character pollution concern. The worry here is less about effects on victims and more about the character of the person using the data. Plaisted identifies three types of character pollution concerns: the "complicity rationale", the "contamination rationale" and the "seepage and self-deception rationales” [48] (p. 1). I take each in turn.

According to the complicity rationale, those who benefit from evil are complicit, because they enter an association that suggests their implicit approval of the original evil ([50] (p. 9) in [48] (p. 6)). According to James Burtchaell, "this situation is detectable when the associate's ability to condemn the activity atrophies” ([50] (p. 9) in [48] (p. 6)). This kind of complicity takes place regardless of one's actual sentiment about the product of evil-simply using the product renders one complicit, for use alone diminishes one's ability to condemn the original act [48] (p. 7). As Ronald Green puts the general sentiment, "Just to pick up a tome containing intimate depictions of the bodies of people murdered by the Nazis, I feel, is to make myself an accessory to the cruel deeds” [51] (p. 548). ${ }^{17}$

However, the complicity rationale is problematic, for it is unclear just how one can be complicit in evil after evil has already been committed. Plaisted is correct to say that this rationale "strains the notion of complicity beyond recognition” [48] (p. 7). Indeed, as Plaisted notes, Burtchaell actually intends a different understanding of complicity, one that suggests that one's stamp of approval on the original evil causes moral deterioration in one's character [48] (p. 7). If this is the sense of complicity Burtchaell has in mind, then he is not invoking the common understanding of complicity according to which one causally contributes to evil, but rather the idea that employing the benefits of evil taints one's character by "harden[ing] one morally” [48] (p. 7). If this is Burtchaell's meaning, then he may come closer to the contamination rationale discussed below.

According to this second type of character pollution concern, the use of products resulting from evil contaminates one's character [48] (p. 9). The idea here is that "those who are willing to appropriate the products of evil fail to display the appropriate amount of moral horror towards the past evil; they have become desensitized morally and... that is the sense in which they are contaminated” [48] (p. 11). However, if this is Burtchaell's intended meaning, he seems mistaken to suggest that the use of a product of evil implies one's approval of or desensitization to the original evil, since it is at least possible to condemn evil while using its products, perhaps even toward good aims. To this point, Plaisted convincingly argues that both the complicity and contamination rationales would appear to rule out many acts that we find perfectly acceptable [48] (p. 8). In the first instance:

If supporters of the complicity rationale seriously wish to maintain that one can become a blameworthy accomplice to the evil of abortion ${ }^{18}$ after the fact by using the tissue of an aborted fetus for benevolent medical purposes, even if one disapproves of abortion, it is difficult to see how their rationale would not also condemn the use of organs from murder victims and other products of evil [48] (p. 8).

Similarly, Plaisted argues that the contamination rationale also condemns too much. By way of the same example, Plaisted asks: “Shouldn’t we view the organs as defiled themselves and anyone who

17 Green himself thinks such sentiments are "highly opaque to analysis" [51] (p. 548).

18 This, of course, assuming that abortion is morally wrong. 
appropriates them for another purpose as consequently defiled as well? If not, then how should we distinguish the donation case from the Nazi data or fetal tissue case?” [48] (p. 11). In sum, without guidance on how to distinguish between complicity or contamination in the case of using Nazi data versus using a murder victim's organs, it is difficult to render compelling either rationale [48] (p. 8).

Finally, Plaisted lists the "seepage and self-deception" character concerns coined by Catherine Kaveny. Seepage takes place when the benefits of evil cause one to view that evil positively [48] (p. 12). To return to the EPA case, seepage would take place if in using the Nazi phosgene gas experiments, the EPA members began to view the data approvingly. Self-deception takes place when one "deludes oneself about one's motives for using the product of evil” [48] (pp. 12-13). To take the same example, if the EPA members convinced themselves that they did not view the data more positively (even though they had), but rather were simply trying to do good, they would be deceiving themselves.

Plaisted notes that these concerns fare better than the previous two because they are case-sensitive. Whether seepage or self-deception actually take place depends on the context, and this means they do not "condemn too many things". However, despite the latter two concerns having some moral force, I concur with Plaisted that character-based concerns in general are ill focused. As he writes, "I find the prospect of someone other than the appropriator being harmed as a result of the appropriator's act more troubling than the prospect of character damage to the appropriator” [48] (p. 13). I agree that, to be morally compelling, the wrong of using data gained from evil should be indexed to victims, not users themselves.

According to the second category of concern, the use of data gained from evil is inherently disrespectful to the victims [45] (p. 255). On this view, since the victims suffered unjustly, the continued use of products arising from those experiments is disrespectful. ${ }^{19}$ Consider here the anger that ensued over eBay's trade in Holocaust memorabilia, including victims' clothing, shoes, Yellow Star of David armbands, a suitcase and a toothbrush. The trade caused international outrage, leading one survivor to remark that such profiting from evil was "so disrespectful to the victims" [52].

However, like the character pollution concern, some argue that this concern is also unconvincing. According to the skeptic, the connection between the knowledge gained from evil and disrespect to victims is far from obvious (e.g., [45] (p. 256); [47] (p. 233)). As Ridley puts it, "There does not appear to be any reason why someone might not be filled with genuine reverence and respect for the victims of an unethical experiment while at the same time benefitting from its results, or attempting to benefit others by using those results” [45] (p. 256). Ridley provides the example of a murder victim. He argues that if a murder caused police to tighten security in the area where the victim was murdered, thus creating a safer neighborhood, it does not follow from this benefit to the neighborhood that the murder victim is disrespected [45] (p. 256). Similarly, it would not follow from the use of Nazi data to improve air pollution regulations that Holocaust victims are disrespected. Ridley explains,

19 Some might object to the victim disrespect concern on the grounds that we cannot disrespect the dead. I do not have the space to enter this debate here. However, for those who doubt the possibility of disrespecting the dead, I think the victim disrespect concern can be also be understood in terms of disrespect to victims' memory, and disrespecting victims' memory can do direct harm to: (1) those individuals who cared for the victims (e.g., their family members, or perhaps activists who fight on behalf of those victims); and (2) in the case of ongoing oppression, to the class of victims who are oppressed by the same practice, but who remain alive (e.g., animals currently being used in experimentation). 
"Only if the beneficiaries ...relish the fact that their good fortune was made possible by the unjust suffering of someone else is anything evidently repulsive going on but then it is these people's attitude towards unjust suffering that is repulsive and not the (mere) fact that they happen to be the beneficiaries of it” [45] (p. 256). In fact, one might instead suggest that benefiting others is a way of respecting those victims, by ensuring they "did not suffer for nothing” [45] (p. 256). I will return to this concern below.

Finally, there is the practice encouragement concern. The practice encouragement concern is forward rather than backward looking and places the focus on potential victims, not users themselves [48] (p. 14). According to this view, the use of products arising from evil implicitly or explicitly encourages others to perpetrate evil in the future [48] (p. 2); [47] (p. 233). This would take place if, for instance, using Nazi data caused researchers to commission and perform horrific experiments on non-consenting individuals. The practice encouragement concern captures a clear and intuitive thought: the use of products of evil is morally unacceptable if it leads to future evil. As Plaisted writes, “...under the encouragement rationale it is not that things associated with evil have any magical property that contaminates the user of them, or that by using such objects we somehow become accomplices after the fact to the original evil; it is rather that using such objects will be wrong if such use will lead to concrete instances of evil in the future" [48] (p. 14). As I find both the victim disrespect and practice encouragement concerns the most convincing, I will say more about each below.

\section{Knowledge Gained from Animal Experimentation}

Although I agree with Plaisted that the character pollution concern is not a convincing basis on which to oppose the use of knowledge gained from evil, I think the case of animal experimentation brings to light the strength of both the victim disrespect and practice encouragement concerns.

Take first the victim disrespect concern. Although Ridley may be correct that there is nothing inherently disrespectful to victims when one uses a product of evil, I do not think we can do away with the victim disrespect concern so readily in the case at hand. This is because while it is reasonable to suppose that a murder victim is not disrespected by the introduction of stricter security into the neighborhood where she was murdered, the same cannot be said about the use of knowledge for which an animal died. To see this, consider that Ridley's murder case presumes nothing about a class of relevant oppressors and oppressed victims. Ridley is not describing a case in which, say: (1) a black man was murdered in a white neighborhood; (2) the murder was racially motivated; and (3) his murder was then used to ensure better security for the white segment of the neighborhood. If this were Ridley's case, then we ought to reconsider the claim that employing the black man's murder to further a white neighborhood's safety does not amount to a form of disrespect. On the contrary, respect for the black victim in this case would involve ensuring greater safety for black people at risk of raciallymotivated crimes. For instance, if Trayvon Martin’s killing, a killing many (reasonably) believe to be a direct result of racism, was used to further the protection of the white segment of the gated community in which he was killed, many would rightly suggest that Martin was disrespected by such a decision. And the reason he would be disrespected is that white domination-and society's systematic expression that white bodies matter more and deserve more protection than black bodies-is part and parcel of the racist worldview that contributed to Martin's death. 
For similar reasons, epistemically benefiting from animal experimentation disrespects animal victims. Just like using Trayvon Martin's killing to ensure safety for a white community would disrespect him, using the results of animal death to benefit humans would likewise disrespect animal victims. The reason is that human domination, and society's systematic expression that human bodies are more morally considerable and worthy than animal bodies, is part and parcel of the speciesist worldview that contributes to animal death. Here, too, there is a relevant class of oppressors and oppressed victims that we cannot deny-in this case, a class of beings that routinely tortures, hunts, captures, kills or eats another class of beings deemed inferior. Since humans as a group directly or indirectly participate in harm to animals for human purposes, the suggestion that animals could be respected by the human use of knowledge acquired through their deaths and suffering is insulting.

Next, unlike the use of Nazi data, using knowledge from animal experimentation provides a clear-cut case of practice encouragement. In the Nazi case, whether the use of Nazi data encourages scientists to perform evil experiments is debatable. It is debatable because there is not a tight connection between the use of Nazi data and the encouragement of future evil. Rather, we can imagine the use of Nazi data accompanied by a condemnation of its origins and future genocidal acts. We can do this largely because the Nazis have ceased murdering Jews and other victims. However, it is more difficult to imagine the accompanying condemnation in the case of knowledge gained from animal experimentation. The reason is that, like a supply and demand model, use of the knowledge presently encourages experimenters to solicit further experimentation the same way consumption of meat encourages meat companies to produce more meat. In other words, once we account for the main purpose behind animal experimentation, namely to yield useful knowledge, affirmations of the practice's usefulness serve to vindicate it. In signaling to experimenters that the practice is useful, the experimenters are thereby directly encouraged to continue the ongoing practice of experimentation. To modify the Nazi example, it is as if the Nazis dropped all other ideological commitments to the extermination of Jews, but still thought the Jews made especially good specimens for research. Then, imagine a user of that research claiming she condemned what the Nazis were doing, but she detached the research's results from the Nazis' acts. One might rightfully query: "Knowing full well that the practice continues for the sake of the knowledge you seek, how can you consistently use the knowledge gained from experimentation, but claim you do not wish to encourage the practice? Without your use, the practice could not survive.” This would be akin to condemning the practice of factory farming, but continuing to consume factory-farmed animals, knowing full well that factory farming's purpose is to produce animals to be consumed.

According to Plaisted, for practice encouragement to take place, the following three conditions must be met: (1) "the person commits an evil act"; (2) "use of the evil product influenced that person to look more favorably on the commission of that act than she would have otherwise"; (3) "without that favorable influence the person would not have committed the act” [48] (p. 15). These three conditions are met in the case of an animal experimenter who kills an animal for knowledge, regards animal experimentation more positively in light of the knowledge gained and who would not have killed the animal if it were not for the prior approbatory feeling that use of the resultant knowledge engendered toward experimentation.

I find Plaisted's conditions overly restrictive. Plaisted suggests that one must commit the evil act in order for encouragement of evil to take place. Plaisted reasons that "merely causing people to look 
more favorably on an evil [...] does not seem to be much of a basis for opposing the use of evil products” [48] (p. 16). To take his example, if one is led to regard elective abortions approvingly as a result of fetal tissue's benefits (assuming elective abortions are wrong), but is not led to get an abortion herself, then evil is not encouraged [48] (p. 16). However, I think Plaisted underestimates what it means for individuals in a society to look positively upon evil acts. A society's favorable viewing of an evil act can still encourage evil in that it can render it more likely that evil be committed or help simply to maintain the status quo. In other words, encouragement need not attach to success. For peer pressure to take place, for instance, one need not successfully pressure someone into a given act, but only to impose the pressure itself and make the pressured act more probable. Similarly, if a society is led to regard animal experimentation approvingly, this need not directly lead to more animal experimentation for the practice to be encouraged. All that is required for encouragement is that the practice be: (1) either rendered more likely than it otherwise would have been; or (2) urged to continue at its current rate.

In fact, Plaisted himself acknowledges a more mitigated type of encouragement when he argues that, sometimes, the "use of a product of evil promotes an environment or context in which the original evil is regarded favorably” [48] (p. 17). In this case:

The benefits of using the evil product have led to a situation in which society views the original evil in a more positive light. If fetal tissue transplantation proved to have substantial therapeutic benefits, it may lead society overall to regard abortion in a more favorable light. This generally more positive attitude towards abortion could make it easier for some to opt for abortion than they could have without the more positive context brought forth by fetal tissue appropriation. I believe this type of situation should be recognized as encouragement of evil just like its more direct counterpart [48] (p. 17).

Here, Plaisted seems to acknowledge that the encouragement of evil can take place regardless of whether a person actually commits evil (Condition 1). It takes place simply if an attitude "could make it easier" for some to commit evil.

On this score, Ronald Green provides a wider and thus more helpful account of practice encouragement. Green's account captures what he calls “indirect encouragement". For indirect encouragement to take place, the benefits of evil need not encourage an actor to commit more evil [51] (p. 550). Indirect encouragement is concerned less with the impact on the evildoer himself and more with the societal impact "of the public rule of conduct that is created by one's acceptance of the benefits of wrongdoing” [51] (p. 550). It is this type of encouragement that Green thinks takes place in the Nazi data case. According to Green, using Nazi data creates an undesirable public rule according to which the scientific community effectively announces that unethically acquired data may be used so long as: "(1) the information can benefit humanity; and (2) there is no chance that those who created the information will be encouraged to repeat their deeds" [51] (p. 550). Given that such a public rule could (but does not necessarily) encourage some researchers to disregard proper moral conduct knowing that their research will be used anyway or to endure temporary criticism in the interest of future gain, it is “prima facie morally questionable” [51] (p. 551).

Of course, the public rule created in the case of animal experimentation even more clearly encourages experimentation itself. The public rule in this case states not only that animal research can 
be used when it benefits humanity (Green's first condition), but that it can be used even though its use will likely encourage more animal experimentation in the future. With such a rule in place, society is surely led to approve of the use of knowledge gained from animal experimentation. Moreover, even if this public rule does not directly cause more animal experimentation to come about, minimally, it helps to maintain the status quo. Indeed, if a negative public rule were in place that led to strong societal disapproval of the use of knowledge gained from animal experimentation, animal experimentation itself would be unable to persist.

\section{Conclusions: Implications for Knowledge Use}

The victim disrespect and practice encouragement concerns provide the most plausible routes to understanding the pro tanto wrong of using knowledge gained from evil. Indeed, in their explanation for why they refuse to publish data arising from Nazi research, the New England Journal of Medicine echoes these two concerns and adds an expressive argument against the data's use. The journal said it would not publish data acquired from injustice because: (1) publishing unjust work violates the principle of respecting the research subject (the victim disrespect concern); (2) could encourage others to do the same in the future (the practice encouragement concern); and (3) refusing to publish the work sends the important message that knowledge, "though important, may be less important to a decent society than the way it is obtained" (in [46], p. 8). I submit that these same three concerns explain with equal force why it is wrong to use knowledge gained from animal experimentation.

At this point, it is worth asking just what these arguments imply for the actual use of knowledge gained from animal experimentation. ${ }^{20} \mathrm{I}$ think there are at least three questions we can ask to help assess whether the pro tanto wrong of using knowledge gained from animal experimentation can be offset: (1) Is the evil recognized and admitted by the knowledge user? (2) Is the reason for the knowledge use morally good? (3) Is it somehow beneficial to the research subjects themselves or at least to the species that was experimented on?

With these questions in mind, it becomes clear that most current uses of knowledge gained from animal experimentation do not overcome the pro tanto wrong established by the victim disrespect and practice encouragement concerns. Consider the animal experimenter him or herself as a relevant knowledge user. First, in the case of animal testing, the experimenter is directly complicit in the pain and death animals undergo; it is accordingly unlikely that the experimenter acknowledges animals as victims of evil. Typically, when one is directly involved in putting animals to death or subjecting them

20 When I refer to knowledge use, I do not intend the use of knowledge by someone who already possesses the relevant knowledge (we cannot simply "unknow”). Rather, I intend use in terms of transfer, i.e., should this knowledge/data/information be transferred to a wider pool of knowledge or to others? Following Robert Nozick's formulation, "a person who acquires a holding in accordance with the principle of justice in acquisition is entitled to that holding” and "a person who acquires a holding in accordance with the principle of justice in transfer, from someone else entitled to the holding, is entitled to the holding" [53] (p. 151). For Nozick, there can only be "justice in holding" if Conditions 1 and 2 are met [53] (p. 151). On my view, since there was no justice in acquisition (i.e., knowledge gained from animal experimentation was not legitimately acquired), then there can be no justice in transfer (i.e., since it was not legitimately acquired in the first place, knowledge gained from animal experimentation cannot legitimately be transferred to others). 
to pain, it is easier to deny that animals are victims at all. ${ }^{21}$ Consider, for instance, the apparent lack of sympathy in the following experimental reports: "First, we'll consider a mutant mouse created in the laboratory...it turns out that, ultimately, this mouse is a disaster: it dies at birth because it cannot control the muscles used for breathing"; "Most interestingly, subjecting a mother rat during pregnancy to moderate stress ${ }^{22}$ (confinement in a clear plastic tube under bright lights) can reduce the levels of testosterone in the developing fetus”; “...there was a determined effort to reproduce.... complete anterograde amnesia for facts and events, in an animal model (preferably an inexpensive animal like a rat)" ([54] pp. 70, 181, 132 in [55] p. 7). These passages reveal that at least some scientists use rather dispassionate language in describing animal subjects ("most interestingly", "an inexpensive animal”, "this mouse is a disaster"), thus suggesting a lack of sympathy for their plight, let alone an acknowledgment of their victim status. ${ }^{23}$

Next, although animal testing sometimes serves morally good aims (consider its role in medicine versus consumer products), as noted earlier, much animal experimentation serves seemingly trivial purposes [25], (p. 65); [22], (p. 117); [56], (p. 311); [49], (p. 99). Lori Gruen describes several experiments like this, including an experiment that tested the effects of LSD on 71 kittens [25] (p. 65). She writes, "While the experimenters noted that 'the behavioral effects of LSD in animals have received monumental attention and literally thousands of studies have dealt with the issue', they decided to go ahead and subject the kittens to the experiments in order to compare the effects on young animals with those on adults” [25] (p. 65). It is difficult to fathom a crucial scientific need for such an experiment.

Finally, the vast majority of experimentation still benefits humans, not animals, as in the case of scientific research aimed at human health or the development of products for human consumption [17] (p. 9). Only rarely are the results of animal experimentation used to benefit animals themselves. ${ }^{24}$

In sum, since (1) the wrongness of animal experimentation is likely to go unacknowledged by the experimenter, (2) the practice often serves frivolous aims and (3) it overwhelmingly benefits humans, not animals, most current-day uses of knowledge from animal experimentation fall prey to the pro tanto wrong and do not offset it. They are accordingly unjust.

I would like to end by canvassing a few objections to my account. First, an objector will protest, given that so many gains have been ill gotten, will not it turn out that a huge sum of knowledge cannot be used on this view? For instance, in 1849, so-called father of gynecology J. Marion Sims performed the first successful fistula operation [58] (p. 29). Since he played such a central role in the development of gynecology, it is not implausible to think that much of the field's knowledge can be traced to his studies. Yet, Sims performed his first vesicovaginal fistula surgeries on enslaved African-American

21 I think this is especially likely in the case of experiments intended to satisfy scientific curiosity.

22 I would also question the description of this as "moderate" stress for the rat. Thanks to an anonymous reviewer for this point.

23 Consider here Joel Marks' call for scientists to formally acknowledge the debt owed to animals in their experimental research [54] (p. 6). However, although formal acknowledgment may constitute a step forward in the fight against animal oppression, if it serves to allay human guilt over the use of animals, it could also constitute a step back.

24 Even in experiments intended to benefit animals, the research may not benefit individual animals, but rather future animals of that species. Moreover, even in studies on animal health, for instance, the benefit is still usually for humans (for instance, to ensure a safe meat supply). Thanks to an anonymous reviewer for this point. 
women [58] (p. 29). As slaves, these women were not asked for consent, and several underwent great pain and suffering (anesthetic was not used) [58] (p. 29). If a line can be traced from Sims' experiments on slaves to current-day gynecological knowledge, then must we cease using gynecological knowledge, as well? Moreover, insofar as all modern medicine has relied on at least some animal (not to mention non-consensual human) experimentation in the past, does this mean we must cease using all modern medical knowledge, as well?

Here, I must emphasize the nature of pro tanto wrongs. Unlike proper wrongs, or acts that are wrong all things considered, pro tanto wrongs are acts that would be wrong were there no other considerations in play. As Shelly Kagan describes it, "a pro tanto reason has genuine weight, but nonetheless may be outweighed by other considerations” [6] (p. 17). In the case of gynecological knowledge, then, it may turn out both that its use is pro tanto wrong, but that a ban on the use of this knowledge would produce more wrongs than it would prevent. These additional wrongs could be strong enough to outweigh the pro tanto wrong of using the knowledge. Indeed, in many cases, it will be too late to block knowledge use, for unlike Nazi data, some knowledge is already entrenched in existing epistemic fields such that preventing its further transfer would be unrealistic (or perhaps impossible), all things considered. This is likely the case with Sims' gynecological knowledge, which is already embedded in a wider, pre-existing field of knowledge. Given these considerations, it would thus be wrong to try to block the knowledge use.

However, although using knowledge gained from Sims' experiments is not likely to encourage today's gynecologists to perform surgery on non-consenting African-American women (the practice encouragement concern), epistemically benefiting from experiments on African-American slaves still meets the victim-disrespect and expressiveness ${ }^{25}$ concerns mentioned above. In light of this, it will still be important to take carefully considered, context-specific measures to diminish the wrong associated with using knowledge reliant on this history. Perhaps widespread awareness and denunciation of experiments and procedures that abused and exploited African-American slaves is an appropriate step. Indeed, since many African-Americans remain distrustful of the healthcare system due to its history of experimentation on and abuse of black bodies [59] (p. 191), perhaps the mandatory acknowledgment and teaching of this history to medical professionals can help contribute to racial justice. Moreover, perhaps medical professionals must commit to combating institutional racism in the healthcare system by taking measures to ensure their practices do not racially discriminate (ideally, these things would be done in their own right as well).

However, the gynecological knowledge case is still importantly different from the animal experimentation case. First, and most importantly, unlike the use of gynecological knowledge, the use of knowledge gained from the ongoing practice of animal experimentation meets the practice encouragement concern. Second, although some knowledge gained from experiments on animals will be entrenched in epistemic fields from which it cannot be readily extracted, data from new and future experiments on animals will not hold such pre-existing ties. In these cases, it will be easier to individuate knowledge and prevent its further transfer. In the case of new and future experiments on animals, then, rejection of the knowledge gained from animal experimentation is morally appropriate.

25 Recall that the New England Journal of Medicine's third reason for refusing to publish Nazi data is that it expresses the message that "though important, [the data] may be less important to a decent society than the way it is obtained." 
Additionally, since animal experimentation's existence is predicated on the usability of its results, the rejection of these results will serve to impugn further animal experimentation.

However, this is not to suggest that the refusal of knowledge is always morally good, for it would be naive to assume that the moral work is done once knowledge is simply refused. Indeed, in some cases, the simple refusal of knowledge may seem ethically pure, yet actively contribute to evil by ignoring or destroying an atrocity's epistemic products. ${ }^{26}$ In other cases, knowledge gained from evil might be used subversively. For instance, consider an animal activist who seeks to use animal experimentation data for the explicit purpose of publicly condemning it or employing it to help heal sick animals who survived experimentation. Here is a case of someone taking up unethically acquired knowledge and using it to combat animal suffering. However, to repeat, insofar as the current employment of knowledge gained from animal experimentation does not offset the pro tanto wrong in these subversive ways, it remains unjust.

One final objection will hold that this proposal is unrealistic, for how can we ever purport to know what knowledge is or is not the product of evil? It is true that we are mired in uncertainty and the limits of our situation. However, this is the nature of ethical life. The same way we can never fully know the effects of our actions, we can never fully know the histories and contexts tied to our present-day situation. Yet ethics still demands that we try. We do our best to predict the effects our actions will have on others. Similarly, we must do our best to combat ignorance and seek to learn about structures and systems of oppression that give rise to present-day institutions, practices and knowledge [60] (p. 140). Such epistemic responsibility will prove key in our efforts to address wrongdoing to both humans and animals.

\section{Acknowledgments}

I would like to thank Andrew Forcehimes, Mylan Engel Jr. and four anonymous reviewers for their helpful feedback.

\section{Conflicts of Interest}

The author declares no conflict of interest.

\section{References}

1. Zamir, T. Killing for Knowledge. J. Appl. Philos. 1990, 23, 17-40.

2. Monamy, V. Animal Experimentation: A Guide to the Issues; Cambridge University Press: Cambridge, MA, USA, 2009.

3. Lafolette, H. Animal Experimentation in Biomedical Research. In The Oxford Handbook of Animal Ethics; Frey, R.G., Beauchamp, T.L., Eds.; Oxford University Press: New York, NY, USA, 2011.

4. Moe, K. Should the Nazi research data be cited? Hastings Cent. Rep. 1984, 14, 5-7.

5. Martin, R. Using Nazi Scientific Data. Dialogue 1986, 25, 403-411.

6. Kagan, S. The Limits of Morality; Clarendon Press: Oxford, UK, 1989.

26 Thanks to José Medina for this point. 
7. Donaldson, S.; Kymlicka, W. Zoopolis; Oxford University Press: New York, NY, USA, 2011.

8. Cohen, C.; Regan, T. The Animal Rights Debate; Rowman \& Littlefield: Lanham, MD, USA, 2001.

9. Nobis, N. Carl Cohen's “Kind” Arguments for Animals Rights and Against Human Rights. J. Appl. Philos. 2004, 21, 43-59.

10. Francione, G.; Garner, R. The Animal Rights Debate: Abolition or Regulation? Columbia University Press: New York, NY, USA, 2010.

11. Singer, P. Animal Liberation and Animal Rights. In Earthcare: An Anthology in Environmental Ethics; Clowney, D., Mosto, P., Eds.; Rowman \& Littlefield: Lanham, MD, USA. 2009.

12. DeGrazia, D. The Ethics of Confining Animals: From Farms to Zoos to Human Homes. In The Oxford Handbook of Animal Ethics; Frey, R.G., Beauchamp, T.L., Eds.; Oxford University Press: New York, NY, USA, 2011.

13. Singer, P. All Animals Are Equal. In Applied Ethics; Singer, P., Ed.; Oxford University Press: New York, NY, USA, 1986.

14. Kittay, E.F. The Personal is Philosophical is Political: A Philosopher and Mother of a Cognitively Disabled Person Sends Notes From the Battlefield. Metaphilosophy 2009, 40, 606-627.

15. Carbone, L. What Animals Want: Expertise and Advocacy in Laboratory Animal Welfare Policy; Oxford University Press: New York, NY, USA, 2004.

16. Taylor, K.; Gordon, N.; Langley, G.; Higgins, W. Estimates for Worldwide Laboratory Animal Use in 2005. Altern. Lab. Anim. 2008, 36, 327-342.

17. Knight, A. The Costs and Benefits of Animal Experiments; Palgrave MacMillan: Oxford, UK, 2011.

18. USDA Statistics for Animals Used in Research in 2012. Available online: http://speakingofresearch.com/2014/02/17/usda-statistics-for-animal-used-in-research-in-2012/ (accessed on18 February 2015).

19. Olsson, I.; Anna, S.; Robinson, P.; Sandøe, P. Ethics of Animal Research. In Handbook of Laboratory Animal Science, Volume I: Essential Principles and Practices; Hau, J., Schapiro, S., Eds.; CRC Press: Boca Raton, FL, USA, 2011.

20. Carbone, L. Pain in Laboratory Animals: The Ethical and Regulatory Imperatives. PLoS One $20116,1-6$.

21. Zimmerman, M. Ethical Considerations in Relation to Pain in Animal Experimentation. Acta Physiol. Scand. 1986, 554, 221-233.

22. Francione, G. Introduction to Animal Rights: Your Child or the Dog? Temple University Press: Philadelphia, PA, USA, 2000.

23. World Health Organization International Agency for Research on Cancer. IARC Monographs on the Evaluation of Carcinogenic Risks to Humans. Tobacco Smoke and Involuntary Smoking. Available online: http://monographs.iarc.fr/ENG/Monographs/vol83/mono83.pdf (accessed on 18 February 2015).

24. Aaltola, E. Animal Ethics. In Encyclopedia of Environmental Ethics and Philosophy; Callicott, J.B., Frodeman, R., Eds.; MacMillan Reference: Farmington Hills, MI, USA, 2009.

25. Gruen, L. Dismantling Oppression: An Analysis of the Connection between Women and Animals. In Ecofeminism: Women, Animals, Nature; Gaard, G., Ed.; Temple University Press: Philadelphia, PA, USA, 1993. 
26. Streiffer, R. The Confinement of Laboratory Animals: Ethical and Conceptual Issues. In The Ethics of Captivity; Gruen, L., Ed.; Oxford University Press: New York, NY, USA, 2014.

27. Demello, M. Rabbits in Captivity. In The Ethics of Captivity; Gruen, L., Ed.; Oxford University Press: New York, NY, USA, 2014.

28. Allen Fox, M. Animal Experimentation: A Philosopher's Changing Views. Between Species 1987, 3, 55-75.

29. Gruen, L. Ethics and Animals; Cambridge University Press: Cambridge, MA, USA, 2011.

30. Gruen, L. The Faces of Animal Oppression. In Dancing with Iris: The Philosophy of Iris Marion Young; Nagel, M., Ferguson, A., Eds.; Oxford University Press: New York, NY, USA, 2009.

31. Felsinger, A. Nine Snow Monkeys Escape from Oregon Animal Testing Lab. Available online: http://planetsave.com/2009/04/04/nine-snow-monkeys-escape-from-oregon-animal-testing-lab/ (accessed on 11 November 2014).

32. Leary, W. Why No Mouse Should Ever Escape AIDS Experiment. Available online: http://www.nytimes.com/1988/02/02/science/why-no-mouse-should-ever-escape-aidsexperiment.html (accessed 11 November 2014).

33. Sharpe, R. The Cruel Deception: The Use of Animals in Medical Research; Thorsons Publishing Limited: London, UK, 1988.

34. Sztybel, D. A Living Will Clause for Supporters of Animal Experimentation. J. Appl. Philos. 2006, 23, 173-189.

35. Kilkenny, C.; Parsons, N.; Kadyszewski, E.; Festing, M.F.W.; Cuthill, I.C.; Fry, D.; Hutton, J.; Altman, D.G. Survey of the Quality of Experimental Design, Statistical Analysis and Reporting of Research Using Animals. PLoS One 2009, 4, e7824.

36. Sztybel, D. Can the Treatment of Animals be Compared to the Holocaust? Ethics Environ. 2006, 11, 97-132.

37. Besser, J. Museum Demands End to PETA's Use of Holocaust Photos. Available online: http://www.jweekly.com/article/full/19449/museum-demands-end-to-peta-s-use-of-holocaust-photos/ (accessed 11 November 2014).

38. Painter, C. The Analogy between the Holocaust and Animal Factory Farming: A Defense. J. Crit. Anim. Stud. 2014, 12, 33-62.

39. Deckha, M. Salience of Species Difference for Feminist Theory. Hastings Women's L.J. 2006, 17, 1-38.

40. Card, C. The Atrocity Paradigm: A Theory of Evil; Oxford University Press: New York, NY, USA, 2002.

41. Davion, V. Feminist Perspectives on Global Warming, Genocide, and Card's Theory of Evil. Hypatia 2009, 24, 160-177.

42. Cohen, B. The Ethics of Using Medical Data from Nazi Experiments. J. Halacha Contemp. Soc. 1990, 19, 103-126.

43. Schafer, A. On Using Nazi Data: The Case Against. Dialogue 1986, 25, 413-419.

44. Post, S. The Echo of Nuremberg: Nazi Data and Ethics. J. Med. Ethics 1991, 17, $42-44$.

45. Ridley, A. Ill-gotten Gains: On the Use of Results from Unethical Experiments in Medicine. Public Aff. Q. 1995, 9, 253-266. 
46. Godlovitch, S. Forbidding Nasty Knowledge: On the Use of Ill-gotten Information. J. Appl. Philos. 1997, 14, 1-17.

47. Zion, D. "Moral Taint" or Ethical Responsibility? Unethical Information and the Problem of HIV Clinical Trials in Developing Countries. J. Appl. Philos. 1998, 15, 231-239.

48. Plaisted, D. The Ethics of Appropriating Evil. Teach. Ethics 2007, 7, 1-23.

49. Taylor, C. Respect for the (animal) dead. In Animal Death; Johnston, J., Probyn-Rapsey, F., Eds.; Sydney University Press: Sydney, Australia, 2013.

50. Burtchaell, J.T. University Policy on Experimental Use of Aborted Fetal Tissue. IRB: Rev. Hum. Subj. Res. 1988, 10, 7-11.

51. Green, R. Benefiting from "Evil”: An Incipient Moral Problem in Human Stem Cell Research. Bioethics 2002, 16, 544-556.

52. Nicol, M.; Murphy, S. Ebay’s sick trade in holocaust souvenirs: Outrage over auctions of Death Camp relics. Available at http://www.dailymail.co.uk/news/article-2485251/Ebays-sick tradeHolocaust-souvenirs-Outrage-auctions-Death-Camp-relics.html (accessed on 11 November 2014).

53. Nozick, R. Anarchy, State, Utopia; Blackwell Publishers: Cambridge, MA, USA, 1974.

54. Linden, D. The Accidental Mind; Harvard University Press: Boston, MA, USA, 2007.

55. Marks, J. On Due Recognition of Animals Used in Research. J. Anim. Ethics 2011, 1, 6-8.

56. Slicer, D. Your Daughter or Your Dog? A Feminist Assessment of the Animal Research Issue. Hypatia 1991, 6, 108-124.

57. Donovan, J. Feminism and the Treatment of Animals: From Care to Dialogue. Signs 2006, 31, 305-329.

58. Ojanuga, D. The Medical Ethics of the "Father of Gynaecology", Dr J Marion Sims. J. Med. Ethics 1993, 19, 28-31.

59. Slavery, R.V. Segregation and Racism: Trusting the Health Care System Ain't Always Easy! An African American Perspective on Bioethics. Louis U. Pub. L. Rev. 1995, 15, 191-235.

60. Medina, J. The Epistemology of Resistance: Gender and Racial Oppression, Epistemic Injustice, and the Social Imagination; Oxford University Press: New York, NY, USA, 2013.

(C) 2015 by the author; licensee MDPI, Basel, Switzerland. This article is an open access article distributed under the terms and conditions of the Creative Commons Attribution license (http://creativecommons.org/licenses/by/4.0/). 